\title{
Respiratory viruses in healthy infants and infants with cystic fibrosis: a prospective cohort study
}

\author{
Insa Korten, 1,2,3 Elisabeth Kieninger, ${ }^{1}$ Shkipe Klenja, ${ }^{4}$ Ines Mack, ${ }^{1,3}$ Njima Schläpfer, ${ }^{1}$ \\ Maria Teresa Barbani, ${ }^{4}$ Nicolas Regamey, ${ }^{1,5}$ Claudia E Kuehni, ${ }^{6}$ Markus Hilty, ${ }_{1}^{4,7}$ \\ Urs Frey, ${ }^{3}$ Meri Gorgievski, ${ }^{4}$ Carmen Casaulta, ${ }^{1}$ Philipp Latzin, ${ }^{1}$ for the SCILD and BILD \\ study groups
}

\begin{abstract}
- Additional material is published online only. To view please visit the journal online (http://dx.doi.org/10.1136/ thoraxjnl-2016-209553).
\end{abstract}

${ }^{1}$ Department of Pediatrics, Pediatric Respiratory Medicine, Inselspital, Bern University Hospital, University of Bern, Bern, Switzerland

${ }^{2}$ Graduate School for Cellular and Biomedical Sciences, University of Bern, Bern,

Switzerland

${ }^{3}$ University Children's Hospital (UKBB), Basel, Switzerland ${ }^{4}$ Institute for Infectious Diseases, University of Bern, Bern, Switzerland

${ }^{5}$ Division of Respiratory Medicine, Children's Hospital Lucerne, Lucerne, Switzerland ${ }^{6}$ Institute for Social and Preventive Medicine, University of Bern, Bern, Switzerland ${ }^{7}$ Department of Infectious Diseases, University Hospital, Bern, Switzerland

\section{Correspondence to} Dr Insa Korten, Division of Respiratory Medicine, Department of Pediatrics, Inselspital and University of Bern, Freiburgstrasse 31, Bern 3010, Switzerland; Insa. Korten@insel.ch

Received 9 October 2016 Revised 24 May 2017

Accepted 26 June 2017

Published Online First

4 August 2017

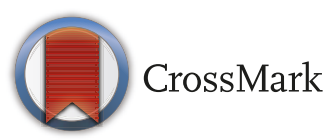

To cite: Korten I, Kieninger $\mathrm{E}_{\text {, }}$ Klenja S, et al. Thorax

2018;73:13-20.

\begin{abstract}
Rationale Acute viral respiratory tract infections in children with cystic fibrosis (CF) are known causes of disease exacerbation. The role of viral infections during infancy is, however, less known, although early infancy is thought to be a crucial period for CF disease development. We prospectively assessed symptomatic and asymptomatic viral detection in the first year of life in infants with CF and healthy controls.

Methods In a prospective cohort study, we included 31 infants with CF from the Swiss Cystic Fibrosis Infant Lung Development Cohort and 32 unselected, healthy infants from the Basel Bern Infant Lung Development Cohort and followed them throughout the first year of life. Respiratory symptoms were assessed by weekly telephone interviews. Biweekly nasal swabs were analysed for 10 different viruses and two atypical bacteria with real-time seven duplex PCR (CF $=561$, controls=712).
\end{abstract}

Measurements and results Infants with CF and healthy controls showed similar numbers of swabs positive for virus (mean $42 \%$ vs $44 \%$; OR $0.91,95 \% \mathrm{Cl}$ 0.66 to $1.26, p=0.6$ ). Virus-positive swabs were less often accompanied by respiratory symptoms in infants with CF $(17 \%$ vs $23 \%$; OR $0.64,95 \% \mathrm{Cl} 0.43$ to 0.95 , $\mathrm{p}=0.026)$. This finding was pronounced for symptomatic human rhinovirus detection (7\% vs $11 \%$; OR 0.52 , $95 \% \mathrm{Cl} 0.31$ to $0.9, \mathrm{p}=0.02$ ).

Conclusions Viral detection is not more frequent in infants with CF and respiratory symptoms during viral detection occur even less often than in healthy controls. It is likely an interplay of different factors such as local epithelial properties and immunological mechanisms that contribute to our findings.

\section{BACKGROUND}

Acute viral respiratory tract infections (ARTIs) in children and adults with cystic fibrosis (CF) play a significant role in morbidity and mortality, causing exacerbations of the disease, a decrease in lung function and often lead to hospitalisations. ${ }^{1-5}$ Especially in children, viral infections are often associated with increased severity of symptoms, ${ }^{56}$ suggesting that viruses play a major role in disease progression and lung damage. However, most knowledge is drawn from periods of exacerbations only and little is known about viruses during periods with little or no symptoms. ${ }^{17-9}$ Additionally, most studies have focused on respiratory infections in patients with

\section{Key messages}

What is the key question?

- How frequent is symptomatic and asymptomatic viral detection in infants with cystic fibrosis (CF) and does it differ from healthy infants?

What is the bottom line?

- Viral detection is equally frequent in infants with CF compared to healthy controls, and symptomatic viral detections occur even less often in infants with CF.

Why read on?

- Our results suggest that early changes in CF lung disease are not due to a higher incidence of viral infections.

CF during childhood or adulthood, ${ }^{2} 10$ while data during infancy remain scarce. ${ }^{11} 12$

Infancy is a crucial period for long-term development and tracking of lung diseases. ${ }^{13-16}$ Several studies have shown impaired lung function and structural lung disease already in infants with $\mathrm{CF},{ }^{17}{ }^{18}$ suggesting that first insults in CF lung disease occur at a very early age. ${ }^{1920}$ Viral infections play an important role at this age as they occur frequently, are regarded as normal and are often unavoidable. With the establishment of the newborn screening for CF in many countries, the first months of life provide new opportunities for prevention of early lung damage. ${ }^{21} 22$ Before possible preventative and/or therapeutic measures targeting early-life viral infections, such as respiratory syncytial virus (RSV) vaccination, can be implemented in infants with CF, a better understanding of the role of viruses and resulting changes in respiratory health during that specific period of development is needed.

In this study, we aimed to assess prospectively symptomatic and asymptomatic viral detection in the first year of life in infants with CF and healthy controls.

\section{METHODS \\ Study design and subjects}

This is a prospective, observational study of infants with CF from the Swiss CF Infant Lung 


\begin{tabular}{|c|c|c|c|}
\hline Characteristic & & $\begin{array}{l}\text { CF } \\
(n=31)\end{array}$ & $\begin{array}{l}\text { Healthy } \\
(n=32)\end{array}$ \\
\hline \multirow[t]{4}{*}{ Anthropometrics } & Sex (m), n (\%) & $13(42)$ & $13(41)$ \\
\hline & $\begin{array}{l}\text { Gestational age at birth } \\
\text { (weeks), mean (SD) }\end{array}$ & $39.1(1.4)$ & $39.8(1.2)$ \\
\hline & Length at birth $(\mathrm{cm})$, mean (SD) & $49.2(1.5)$ & $49.7(2.1)$ \\
\hline & Birth weight (kg), mean (SD) & $3.2(0.4)$ & $3.4(0.5)$ \\
\hline \multirow[t]{4}{*}{ Season of birth* } & Winter, n (\%) & $10(32)$ & $8(25)$ \\
\hline & Spring, n (\%) & $12(39)$ & $7(22)$ \\
\hline & Summer, n (\%) & $3(10)$ & $9(28)$ \\
\hline & Autumn, n (\%) & $6(19)$ & $8(25)$ \\
\hline Pregnancy & Smoking in pregnancy, $\mathrm{n}(\%)$ & $7(23)$ & $7(22)$ \\
\hline Birth & Cesarean section, n(\%) & $2(6)$ & $3(9)$ \\
\hline Nutrition & Breast-feeding, n (\%) & $26(84)$ & $32(100)$ \\
\hline Family history & Maternal atopy, n (\%) & $8(26)$ & $9(28)$ \\
\hline \multirow[t]{5}{*}{ Environment } & Siblings, $n$ (\%) 0 & $16(52)$ & $7(22)$ \\
\hline & 1 & $10(32)$ & $15(47)$ \\
\hline & $\geq 2$ & $5(16)$ & $10(33)$ \\
\hline & Childcaret, n (\%) & $0(0)$ & $7(22)$ \\
\hline & Parental smoking & $12(39)$ & $4(12.5)$ \\
\hline \multirow[t]{3}{*}{ Parental education $\ddagger$} & Low & $6(19)$ & $3(9)$ \\
\hline & Middle & $9(29)$ & $13(41)$ \\
\hline & High & $16(52)$ & $16(50)$ \\
\hline \multirow[t]{2}{*}{ Measurements } & 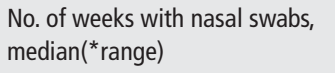 & $19(5-27)$ & $23(15-26)$ \\
\hline & $\begin{array}{l}\text { Nasal swabs during antibiotics§, } \\
\text { median ("}{ }^{*} \text { range) }\end{array}$ & $3(0-13)$ & $0(0-1)$ \\
\hline \multirow[t]{3}{*}{ CF genotypeף } & $\begin{array}{l}\text { No residual CFTR function } \\
\text { (class I and/or II), } \mathrm{n}(\%)\end{array}$ & $21(68)$ & \\
\hline & $\begin{array}{l}\text { Residual CFTR function } \\
\text { (class I/II and III-VI), } \mathrm{n}(\%)\end{array}$ & $6(19)$ & \\
\hline & Unknown CFTR function, n (\%) & $4(13)$ & \\
\hline
\end{tabular}

* Season of birth is categorised with the calendric definition of season: *Winter 22.12.-20.3.; spring 21.3.-20.6.; summer 21.6-22.9.; fall 23.9.-21.12.) tChildcare is defined as attending childcare in the first year of life at any time point. ¥Parental education is categorised into low ( $<4$ years of apprenticeship), middle ( $<4$ years of apprenticeship) and high (tertiary education).

$\S$ Samples taken during periods with application of any antibiotics.

IInfants with cystic fibrosis (CF) were grouped in patients with no residual Cystic Fibrosis Transmembrane conductance Regulator (CFTR) function: two known copies of class I and/or II mutations; residual CFTR function: one class I or II mutation plus one other mutation, unknown CFTR function: $\geq 1$ mutation not classified or unknown mutation, however, with two copies of disease causing mutations.

Development cohort, ${ }^{23}{ }^{24}$ and of healthy infants from the Basel Bern Infant Lung Development ${ }^{25}$ cohort. We included 31 infants with $\mathrm{CF}$ and 32 healthy, unselected infants born between 2010 and 2014. Infants with CF had been diagnosed with the Swiss CF neonatal screening, and thus most did not present with respiratory symptoms when enrolled in the study. An anterior nasal swab for viral assessment (FLOQSwabs, in UTM-RT (Copan, Italia)) was collected biweekly, starting in the fifth week of life and mailed into the laboratory. A weekly telephone interview was performed by study nurses to assess respiratory health. Details of the study population are displayed in table 1 . The study was performed in Bern and approved by the Ethics Committee of Bern, Switzerland. Informed consent was obtained from the parents.

\section{Virological analysis}

Ten different viruses and two atypical bacteria were analysed in each sample and used as outcome parameters in our analysis: influenza A, influenza B, RSV, human metapneumovirus, adenovirus, human bocavirus (hBoV), human rhinovirus/enterovirus (HRV), human parechovirus, human coronavirus, human parainfluenzavirus (hPIV), Mycoplasma pneumoniae and Chlamydia pneumoniae.

The samples were analysed by real-time (combination of seven duplex) PCR, using the Respiratory Multi Well System r-gene (Argene/bioMérieux, Marcy l'Etoile, France), according to the manufacturer's instructions. Sampling quality, extraction and amplification in every sample were evaluated using a HPRT1 cellular gene control (CC) assay using the duplex Rhino\&EV/ $\mathrm{CC}$ r-gene. Samples showing an exponential amplification curve with a CT (crossing threshold) value $\leq 40$ were considered as positive. Thus, all samples with a CT value $>40$ were excluded in the final analysis due to low quality. For easier reading, the term viral analysis is used, although two atypical bacteria were also included in the analysis.

\section{Respiratory symptoms}

In weekly standardised telephone interviews, symptoms of lower and upper respiratory tract infections, wheeze and/or cough were recorded. ${ }^{25}$ Rhinitis (runny or blocked nose) was independently assessed as the most common upper respiratory symptom. Upper respiratory tract infections (URTI) were defined if cough with or without rhinitis was recorded. A lower respiratory tract infection (LRTI) was defined as wheeze or breathing difficulties accompanied by upper respiratory tract symptoms or elevated temperature over more than two consecutive days. In addition, we combined upper and lower respiratory symptoms as having 'any symptoms'.

We defined viral detection as swabs positive for any virus, irrespective of symptoms and asymptomatic viral detection as swabs positive for any virus but free of symptoms. Symptomatic viral detection was defined as swabs positive for any virus accompanied by respiratory symptoms occurring up to 7 days before and 7 days after the sample was taken.

\section{Additional risk factors or confounders}

Hospital records and questionnaires provided information on the family, maternal, sociodemographic and environmental histories in the prenatal, perinatal and postnatal periods. Changes in host and environmental factors were documented during the weekly standardised phone interview. Time-invariant factors included in our study were sex, maternal atopic disease (maternal asthma, hay fever, eczema), parental education (categorised into low (<4 years of apprenticeship), middle (at least 4 years of apprenticeship) and high (tertiary education)) and presence of older siblings. Time-variant factors included were age and season of sampling, breast feeding ('current' (yes/no) at time of swab) and childcare ('current' (yes/no) at time of swab).

\section{Statistical analysis}

Initially, the proportion of all samples (as per cent) in which a virus was detected was compared between healthy infants and infants with CF. We used multivariable logistic regression, including a random effect, to account for multiple measurements in the same individuals to investigate: (1) differences in viral detection between infants with $\mathrm{CF}$ and healthy infants; (2) possible determinants for viral detection; (3) differences in symptomatic viral detection between infants with $\mathrm{CF}$ and 
healthy controls; (4) differences in virus species between infants with CF and healthy controls.

Results are presented as ORs with 95\% CIs and $\mathrm{p}$ values; healthy infants were always considered as baseline. After fitting a univariable model (no adjustment), we fitted adjusted models accounting, in a first step, for season and age, as both age and season have been shown to influence viral detection. ${ }^{26}$ In a further step, we also considered following potential determinants: having siblings, attending childcare, breast feeding, parental education, maternal atopy, gender. ${ }^{26}{ }^{27}$ We also fitted separate models for CF and healthy infants, including simultaneously age, season, breast feeding, siblings, in the healthy group attending childcare and in the CF group application of antibiotics and Cystic Fibrosis Transmembrane conductance Regulator function. Due to the lower number of positive measurements, analysis for differences in individual virus species (4) was performed in a univariable model only and not for symptomatic episodes separately (except HRV). Despite rigid sampling instructions, the number of low-quality swabs was higher in the infants with CF. Therefore, we performed different sensitivity analyses: we repeated the main analyses: (1) selecting additional and different CT cut-off values (35/45); (2) including all virus positive swabs irrespective of CT value; (3) excluding infants with a high number of low-quality samples (online supplementary material, table E1). Sensitivity analysis confirmed that the study design was appropriate and results were robust (for details, see online supplementary material and table E1). P values $\leq 0.05$ were considered statistically significant. All analyses were performed using Stata V. 13 and GraphPad Prism 5.

For details on inclusion criteria, nasal swab procedure, virus analysis, risk factor assessment, statistical analysis and power calculation see online table OLS.

\section{RESULTS}

\section{Study population}

A total of 1273 biweekly nasal swabs from 32 healthy infants (712 swabs) and 31 infants with CF (561 swabs) throughout the entire first year of life were analysed for virological characterisation after exclusion of low-quality swabs (see figure 1). Demographics did not differ between groups. However, the following risk factors differed between the two groups: application of antibiotics, number of siblings and childcare attendance (table 1).

\section{Differences in viral detection between infants with CF and healthy infants}

Quantitative analysis of virus (measured semiquantitative, analysing CT values) did not differ between the two groups (results not shown). Thus, for further analysis we only differentiated between samples positive or negative for virus (for additional sensitivity analyses, see statistical analysis in the online supplementary material and table E1). Results of asymptomatic

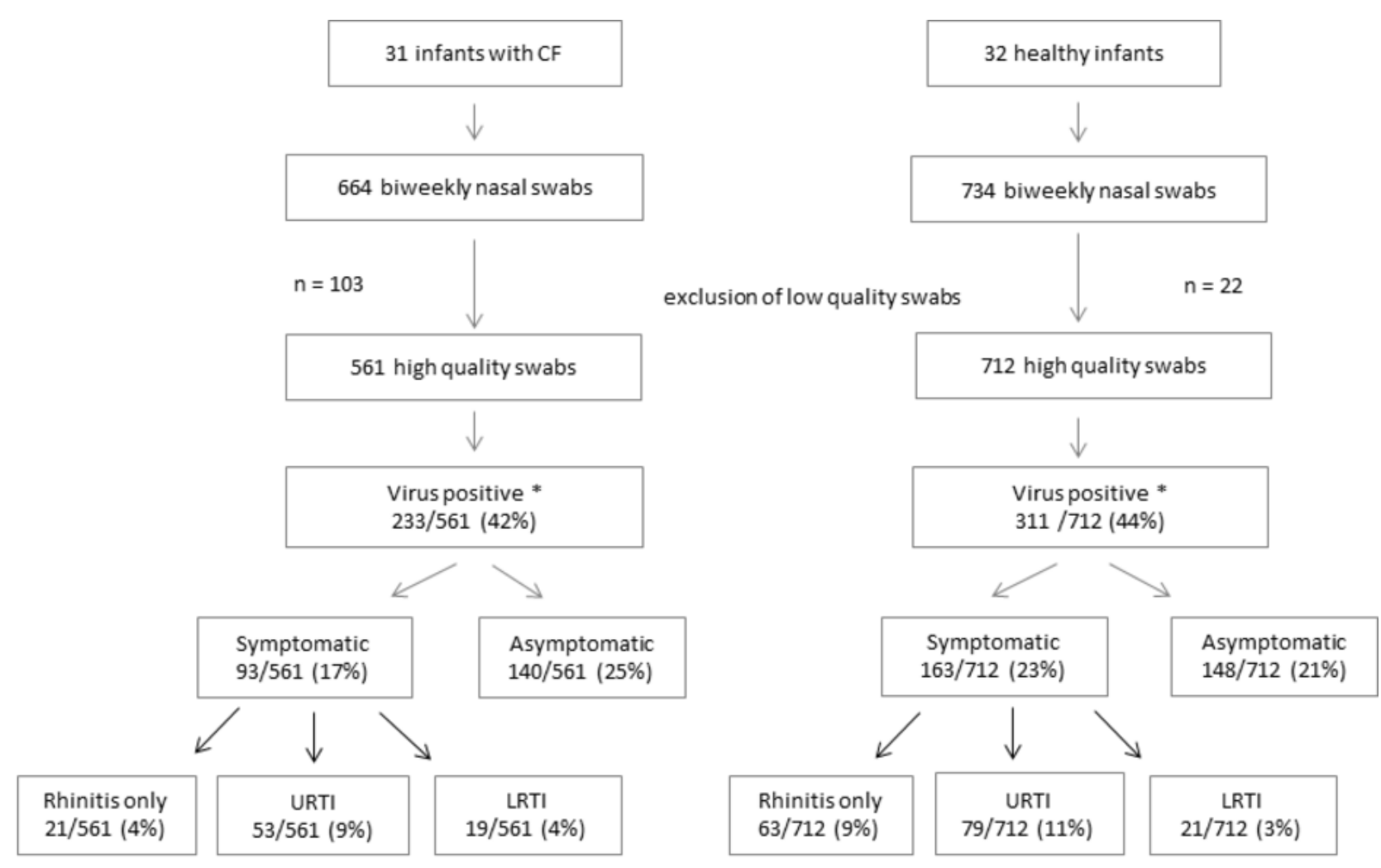

*for detailed virus analysis see table 2

Figure 1 Flowchart of virological analysis in infants with CF and healthy infants, including information on excluded samples. CF, cystic fibrosis; LRTI, lower respiratory tract infection; URTI, upper respiratory tract infection. 
Table 2 Viral detection in healthy infants and infants with CF

\begin{tabular}{|c|c|c|c|c|}
\hline \multirow[t]{2}{*}{ Virus } & \multicolumn{2}{|c|}{ Positive samples * } & \multicolumn{2}{|c|}{ Positive samples accompanied by symptoms $†$} \\
\hline & $\begin{array}{l}\text { CF } \\
n(\%)\end{array}$ & $\begin{array}{l}\text { Healthy } \\
\text { n (\%) }\end{array}$ & $\begin{array}{l}\text { CF } \\
n(\%)\end{array}$ & $\begin{array}{l}\text { Healthy } \\
\text { n (\%) }\end{array}$ \\
\hline Any virus & $233(42)$ & $311(44)$ & $93(17)$ & $163(23)$ \\
\hline$>1$ virus & $52(9)$ & $46(6)$ & $16(3)$ & $30(4)$ \\
\hline HRV & $110(20)$ & $177(25)$ & $39(7)$ & $78(11)$ \\
\hline $\mathrm{hCoV}$ & $41(7)$ & $52(7)$ & $8(1)$ & $12(2)$ \\
\hline ADV & $27(5)$ & $43(5)$ & $4(1)$ & $11(2)$ \\
\hline hPIV & $14(2)$ & $35(5)$ & $5(1)$ & $15(2)$ \\
\hline hBoV & $53(9)$ & $18(3)$ & $9(2)$ & $5(1)$ \\
\hline RSV & $21(4)$ & $17(2)$ & $8(1)$ & $8(1)$ \\
\hline $\mathrm{hPeV}$ & $8(1)$ & $8(1)$ & $0(0)$ & $2(0)$ \\
\hline $\mathrm{hMpV}$ & $5(1)$ & $5(1)$ & $2(0)$ & $2(0)$ \\
\hline Mycoplasma pneumoniae & $9(2)$ & $4(1)$ & $2(0)$ & $1(0)$ \\
\hline Influenza B & $2(0)$ & $2(0)$ & $0(0)$ & $0(0)$ \\
\hline Influenza A & $0(0)$ & $1(0)$ & 0 & $1(0)$ \\
\hline Chlamydia pneumoniae & $1(0)$ & $0(0)$ & $0(0)$ & $0(0)$ \\
\hline
\end{tabular}

Infants with CF ( $n=31$, samples $n=561)$; healthy infants ( $n=32$, samples $=712$ ).

Total number of samples $n(\%) ; \%$ of samples refer always to total number of samples: in infants with $C F, n=561(100 \%)$; in healthy infants, $n=712(100 \%)$.

*Nasal swabs with viral detection irrespective of symptoms.

†Nasal swabs with viral detection and respiratory symptoms. For this analysis, samples with more than one virus were excluded.

ADV, adenovirus; CF, cystic fibrosis; hBoV, human bocavirus; HCoV, human coronavirus; hMpV, human human metapneumovirus; $h P e V$, human parechovirus; $h P I V$, human

parainfluenzavirus; HRV, human rhinovirus; RSV, respiratory syncytial virus.

and symptomatic viral detection in general and for the different viruses are given in table 2.

Prevalence of viral detection was similar in infants with CF and healthy infants on average. Viruses were found in 42\% (SD 15; minmax 11-65) of swabs in infants with CF and in 44\% $(15 ; 17-77)$ of swabs in healthy infants (OR from multilevel logistic regression: 0.92 ; $95 \%$ CI 0.67 to $1.25 ; \mathrm{p}=0.6$, table 3 ).

The proportion of samples per individual in which a virus was detected was similar in both study groups, indicating that possible differences were not due to outliers with extreme frequent or rare viral detection (figure 2).

Similarly, age of first viral detection did not differ between infants with CF and healthy infants, and most infants had their first viral detection within the first 4 months of life (healthy infants $88 \%$ and infants with CF 90\%).

\section{Risk factors for viral detection}

Viral detection became more common with age; this was similar in both cohorts. Thus, infants with $\mathrm{CF}$ and healthy infants showed no differences in viral detection in the different age groups (table 4 and online supplementary material, figure E1, online supplementary material).

We did not observe that viral detection in our cohort was more frequent in children with any of the known risk factors (season, breast feeding, siblings, childcare; table 4). The effect of childcare could not be investigated in infants with CF because none of them attended daycare. In the CF group, we did not find an association of viral detection with genotype or the application of antibiotics (table 4).

\section{Symptomatic viral detection in infants with CF and healthy infants}

When a virus was present, infants with CF were reported less often to have respiratory symptoms than healthy controls (symptoms in $17 \%$ (SD 11 ; $\min -\max 0-45)$ vs $23 \%(12 ; 0-45)$; OR from multilevel logistic regression: $0.67 ; 95 \%$ CI 0.46 to $0.96 ; p=0.03$, table 3). Viral detection accompanied by more severe symptoms (URTIs and LRTIs) was not different between infants with CF

Table 3 Difference in viral detection in healthy infants and infants with CF

\begin{tabular}{|c|c|c|c|c|c|c|c|c|c|c|c|}
\hline & \multirow{2}{*}{$\begin{array}{l}\text { CF } \\
n(\%)\end{array}$} & \multirow{2}{*}{$\begin{array}{l}\text { Healthy } \\
\text { n (\%) }\end{array}$} & \multicolumn{3}{|c|}{ Unadjusted model } & \multicolumn{3}{|c|}{ Adjusted model $^{\mathrm{a}}$} & \multicolumn{3}{|c|}{ Adjusted model $^{b}$} \\
\hline & & & OR & $95 \% \mathrm{Cl}$ & $p$ & OR & $95 \% \mathrm{Cl}$ & $p$ & OR & $95 \% \mathrm{Cl}$ & $p$ \\
\hline Viral detection & $233(42)$ & $311(44)$ & 0.92 & 0.67 to 1.25 & 0.6 & 0.91 & 0.66 to 1.26 & 0.6 & 0.93 & 0.64 to 1.37 & 0.7 \\
\hline $\begin{array}{l}\text { Symptomatic viral } \\
\text { detection }\end{array}$ & $93(17)$ & $163(23)$ & 0.67 & 0.46 to 0.96 & 0.03 & 0.64 & 0.43 to 0.95 & 0.026 & 0.71 & 0.46 to 1.13 & 0.15 \\
\hline HRV detection* & $84(15)$ & $143(20)$ & 0.67 & 0.47 to 0.99 & 0.044 & 0.63 & 0.42 to 0.95 & 0.026 & 0.56 & 0.36 to 0.87 & 0.009 \\
\hline $\begin{array}{l}\text { Symptomatic HRV } \\
\text { detection* }\end{array}$ & $39(7)$ & $78(11)$ & 0.58 & 0.35 to 0.97 & 0.036 & 0.52 & 0.31 to 0.9 & 0.02 & 0.58 & 0.31 to 1.07 & 0.08 \\
\hline
\end{tabular}

Unadjusted and adjusted OR from logistic regression models for viral detection and symptomatic viral detection comparing healthy infants and infants with CF.

*For HRV analysis, swabs with codetection of other viruses were excluded, outcome was symptomatic and asymptomatic viral detection and HRV detection (yes/no), reference category samples free of virus/free of HRV exposure was CF status, reference category = healthy infants, $p=p$ value adjusted model ${ }^{a}$ : adjusted for age and season adjusted

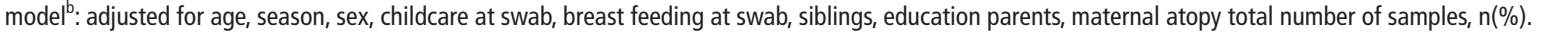

CF, cystic fibrosis; HRV, human rhinovirus. 


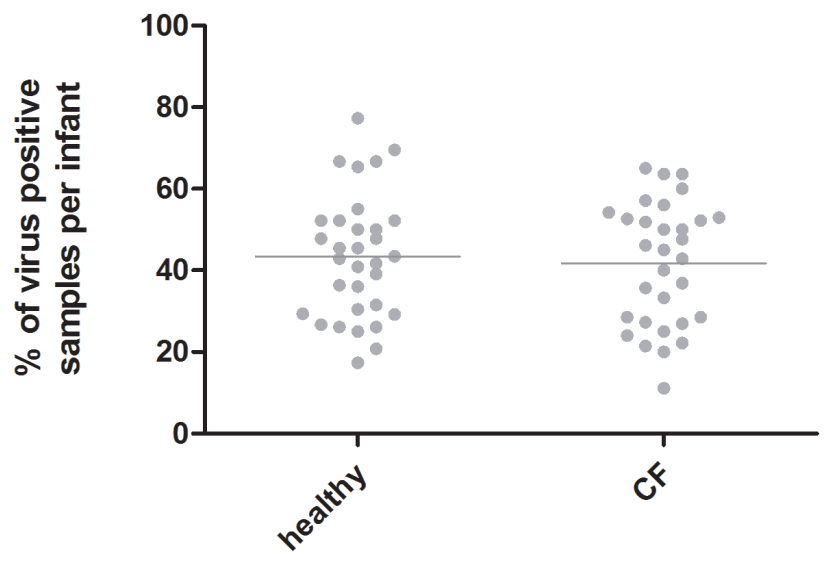

Figure 2 Viral detection in the first year of life. Percentages (\%) of positive samples per infant overall during the study period are shown, and mean of viral detection in the first year of life in healthy infants and infants with CF is given. CF, cystic fibrosis.

and healthy infants (URTI: OR $0.8,95 \%$ CI 0.58 to $1.21, \mathrm{p}=0.3$; LRTI: $1.2,95 \%$ CI 0.58 to $2.33, \mathrm{p}=0.7)$. Findings remained stable when investigating the percentages of samples with viral detection accompanied by symptoms per infant over the entire study period (figure 3a), assuring results were not due to outliers with extreme frequent or rare symptomatic viral detection.

\section{Detection of different viruses in infants with CF and healthy infants}

HRV was the most frequent virus detected in both study groups, but occurred less frequently in infants with CF (20\% vs 25\%;
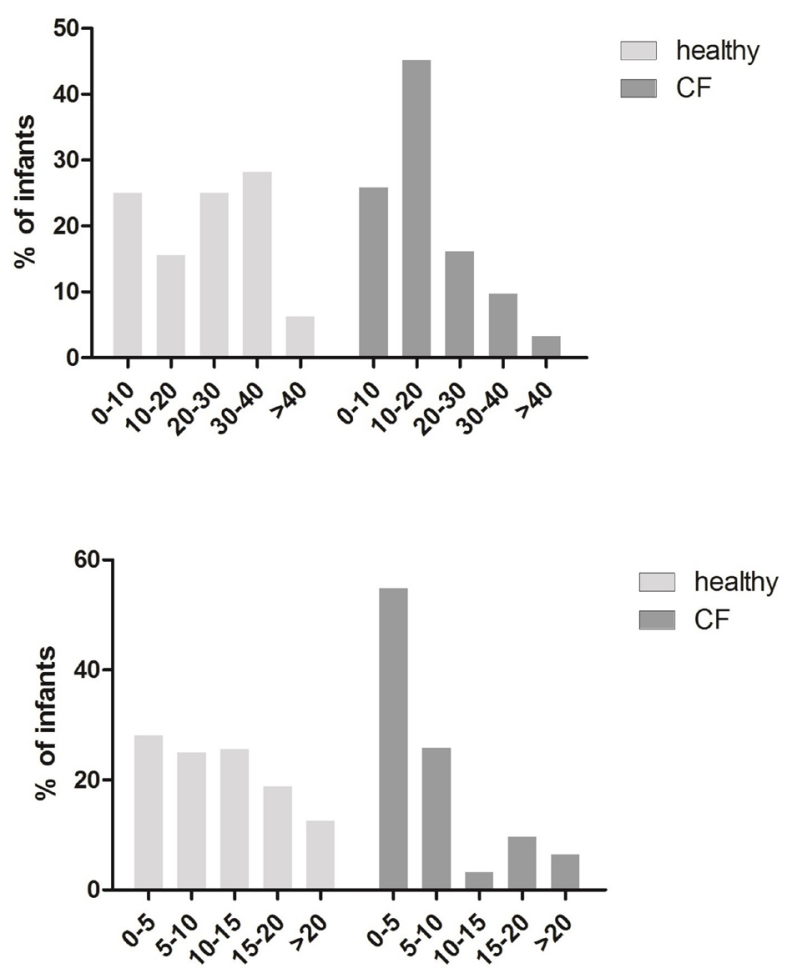

Figure 3 Distribution of viral detection. Frequency of (a) symptomatic viral detection and (b) symptomatic human rhinovirus detection in percentages (\%). Displayed is the proportion of infants (in \%), with very low $(<10 \%)$, low $(10 \%-20 \%)$, medium $(20 \%-30 \%)$, frequent $(30 \%-40 \%)$ or very frequent $(>40 \%)$ viral detection over the whole study period. Less frequent symptomatic detections in infants with CF were found. CF, cystic fibrosis.

OR from multilevel logistic regression: OR 0.67; 95\% CI 0.47 to $0.99 ; \mathrm{p}=0.044)$. The same was found for symptomatic HRV detection (OR 0.58 ; 95\% CI 0.35 to 0.97 ; $\mathrm{p}=0.036$, unadjusted

Table 4 Risk factors for viral detection in healthy infants and infants with cystic fibrosis (CF) separately

\begin{tabular}{|c|c|c|c|c|c|c|}
\hline \multirow[b]{2}{*}{ Exposure: risk factor } & \multicolumn{3}{|c|}{ Healthy infants } & \multicolumn{3}{|c|}{ Infants with CF } \\
\hline & OR & $95 \% \mathrm{Cl}$ & $\mathrm{p}$ & OR & $95 \% \mathrm{Cl}$ & $\mathrm{p}$ \\
\hline Gender* & 1.09 & 0.68 to 1.74 & 0.7 & 0.76 & 0.48 to 1.21 & 0.3 \\
\hline Breast feeding & 1.26 & 0.78 to 2.04 & 0.3 & 0.94 & 0.60 to 1.48 & 0.8 \\
\hline Siblings§ & 1.34 & 0.77 to 2.32 & 0.3 & 1.12 & 0.73 to 1.97 & 0.5 \\
\hline $\begin{array}{l}\text { Aget } \\
3-6 \text { months }\end{array}$ & 1.27 & 0.80 to 2.02 & 0.3 & 1.32 & 0.76 to 2.32 & 0.3 \\
\hline 6-9 months & 1.31 & 0.79 to 2.17 & 0.3 & 1.52 & 0.82 to 2.82 & 0.2 \\
\hline 9-12 months & 2.14 & 1.18 to 3.88 & 0.013 & 1.80 & 1.81 to 3.41 & $0.08^{\#}$ \\
\hline Season $\neq$ spring & 0.96 & 0.62 to 1.49 & 0.9 & 0.73 & 0.43 to 1.25 & 0.3 \\
\hline Summer & 1.10 & 0.70 to 1.71 & 0.7 & 1.03 & 0.62 to 1.73 & 0.9 \\
\hline Fall & 0.95 & 0.61 to 1.47 & 0.8 & 1.22 & 0.73 to 2.05 & 0.5 \\
\hline Antibiotics§ & & - & & 0.63 & 0.33 to 1.20 & 0.2 \\
\hline CF genotypeף & & - & & 0.76 & 0.54 to 1.07 & 0.1 \\
\hline Childcare & 1.46 & 0.80 to 2.67 & 0.2 & & - & \\
\hline
\end{tabular}

Adjusted OR for viral detection investigating different risk factors, stratified for CF status from multilevel logistic regression. Results are displayed after adjustment for all tested risk factors, outcome was viral detection in general (yes/no), reference category samples free of virus, analysis was done separately for healthy infants and infants with $\mathrm{CF}$. $\mathrm{p}=$ p value, reference category for exposures: ${ }^{*}$ baseline $=$ male; ${ }^{\S}$ baseline $=$ no siblings; tbaseline $=$ age $0-3$ months, $\neq$ baseline $=$ winter; $\$$ baseline $=$ before any antibiotics $(A B)$ compared with samples during $A B$; samples after first application of $A B$ are not shown, no different result to samples before first $A B$ application; $\rceil$ baseline $=$ no residual $C y$ stic Fibrosis Transmembrane conductance Regulator function.

p Value for interaction between listed exposures and healthy infants and infants with $C F$, model including all children always $p>0.3$, \# $=$ trend after adjustment for all confounders, in a model only considering age and season, significant (OR 2.04; $95 \% \mathrm{Cl} 1.12$ to $3.70 ; \mathrm{p}=0.019)$. 
and adjusted analyses are shown in table 3). This was most pronounced below the age of 6 months (HRV detection: OR $0.53 ; 95 \%$ CI 0.31 to $0.92 ; \mathrm{p}=0.025$ and symptomatic HRV detection: OR 0.43 ; 95\% CI 0.21 to 0.879 ; $\mathrm{p}=0.022$ respectively, adjusted for season). Results were similar if the percentages of samples with symptomatic HRV detection were analysed per infant over the entire study period, indicating that they were not due to outliers (figure $3 \mathrm{~b}$ ).

Persistence of HRV in two or more consecutive samples was not frequent and did not differ between infants with CF and healthy infants (OR 1.1; 95\% CI 0.63 to 1.97 ; $\mathrm{p}=0.8$ ). HRV detection in two consecutive samples was seen 18 times in healthy and 15 times in infants with CF. HRV detection in three or more consecutive samples was rare in both groups (three consecutive samples 12 (healthy) vs 8 (CF); four consecutive samples: 3 vs 2 ; five consecutive samples: 1 vs 1 , six consecutive sample 0 vs 1 ). This was also true investigating persistent symptomatic HRV detection or asymptomatic detection separately and analysing episodes starting with symptomatic HRV detection and continuing with asymptomatic detection (results not shown).

All other viruses were detected in only $10 \%$ of the nasal samples or less (table 2). HBoV detection was more frequent in infants with CF (OR 4.2; 95\% CI 2.14 to 8.24; p<0.001), while hPIV occurred less often (OR $0.5 ; 95 \%$ CI 0.26 to $0.93 ; \mathrm{p}=0.029$ ). Other viruses occurred rarely and there were no clear differences in the different viruses that were detected between infants with CF and healthy infants (see table 2 and online supplementary material, figure E2, online supplementary material).

\section{DISCUSSION}

In this prospective longitudinal study, we investigated viral detection in infants with CF compared with healthy controls in the first year of life. We could distinguish symptomatic and asymptomatic detection by weekly monitoring of respiratory symptoms. In a total of 1273 biweekly nasal samples, each analysed for 10 different viruses and two atypical bacteria, prevalence of viral detection was not more frequent in infants with CF. Surprisingly, in infants with CF, respiratory symptoms were even less commonly reported during viral detection. Although HRV was the most frequently detected virus in both groups, it occurred less often in infants with $\mathrm{CF}$, whereas hBoV occurred more frequently.

To our knowledge, this is the first study to compare the prevalence of viral detection during symptomatic and asymptomatic episodes in the first year of life in infants with CF and healthy controls. Hiatt et $a l^{28}$ found the same number of upper respiratory infections in children with CF and healthy controls below the age of 2 years, but more LRTIs in the CF group. In contrast to our study, viral analysis was only performed during symptomatic periods, where RSV and influenza were detected more frequently in healthy infants. In addition, children with $\mathrm{CF}$ had persisting lung function changes after viral infection. ${ }^{28} \mathrm{~A}$ study in older children comparing viral detection in CF and healthy subjects found no difference in the prevalence of viruses during ARTIs, but reported prolonged and more frequent LRTIs in children with $\mathrm{CF}^{29}$

Our results also show a comparable cumulative incidence of viral detection between patients with $\mathrm{CF}$ and healthy controls, but symptomatic detection was not more frequent, of longer duration, or more severe in infants with CF. However, the number of severe LRTIs in our study subjects was low; thus, we cannot draw final conclusions on this parameter. The impact of severe viral infection needs to be investigated in a larger number of infants capturing higher numbers of LRTIs. A number of studies in older children with CF showed a high prevalence of viral infections during ARTIs, leading to acute and chronic respiratory complications, impaired lung function and/or disease progression. $^{24} 68$ 30-34 A diminished immune response towards viruses, leading to more severe viral infections and higher viral burden, has also been reported in older patients with CF. ${ }^{3536}$ Overall, concordant data from ex vivo and in vitro studies have shown an impaired antiviral response in patients with more pronounced disease. ${ }^{35-38}$ Our results suggest that this is not the case during the first year of life. Whether this is due to less severe underlying disease or to the ongoing development of the immune system is not known. Thus far, there are only a few studies investigating viral detection in infancy, and the role of immunologic pathways in CF lung disease, especially in early infancy, remains unclear. Studies using bronchoalveolar lavage fluid of infants and children with CF showed that viral ${ }^{11}$ and bacterial ${ }^{39}$ infections lead to inflammatory and immune processes. It remains unknown to what extent the early inflammatory airway response in young infants is independent of infections. The fact that, even in our study, the prevalence of HRV detection increased with older age in the CF group compared with healthy controls could already be an early sign of possible changes in the immune response or susceptibility to HRV, further leading to increased numbers of infections later in life. This is in line with a recent study, ${ }^{9}$ showing more frequent HRV detection in children with CF during respiratory infections and asymptomatic episodes compared with healthy controls. ${ }^{9}$ An additional indicator of different reactions to viruses already in early life might be the surprisingly high number of $\mathrm{hBoV}$ detection in our $\mathrm{CF}$ cohort. As hBoV is a relatively newly discovered virus, with an unknown role in lung disease, but a probable role in ARTIs, ${ }^{40}$ further studies are needed for the interpretation of this finding. ${ }^{41}$

The age at the first viral detection did not differ between groups. This means that infants with CF do not show earlier viral detection or increased susceptibility towards viruses per se. It is possible that later in life, and with advanced disease, the chronic inflammatory processes in the airways influence the innate immunity of the airway epithelium. More probable is that several factors compound simultaneously: specific viruses, time point of infection, genetics, bacteria and others. Furthermore, in this study, infants were included shortly after birth and diagnosed by newborn screening, and were, thus, mainly asymptomatic, which clearly differs to other studies. Hence, due to early diagnosis, all infants in our cohort received physiotherapy, daily inhalation and medical care on a regular base with a CF specialist from birth on. This could have beneficial preventative effects that could delay disease progression, which could serve as an additional explanation as to why viral detections were not as severe as in the older age groups. Additionally, given that none of the infants with CF attended childcare and less infants with CF had older siblings compared with healthy controls, environmental exposure to viruses was very likely lower for infants with CF compared with healthy controls. This could have, at least partially, contributed to comparable viral detection rates between groups. However, duration of shedding did not differ between the two groups, as there was no difference in the frequency of HRV detection in two or more consecutive samples.

A major strength of our study is the prospective study design and the standardised, dense, biweekly sampling, which was not restricted to scheduled visits or periods of respiratory illness. Detailed information about sociodemographic factors and the weekly documentation of changes in environmental exposures allowed us to adjust for different confounding factors. We were 
able to investigate for the first time dynamics of viral detection in the first year of life, over a time period of 10 months for each study subject. Due to the high number of different viruses analysed, it was possible to distinguish between samples free of virus, viral detection and viral codetection. This improved the accuracy of our results.

Furthermore, including infants with $\mathrm{CF}$ and controls allowed a comparison between diseased and otherwise healthy infants. This comparison is important to detect possible differences in viral detection in $\mathrm{CF}$, and enables us to draw conclusions for future treatment options.

A limitation is the small number of study infants. To detect further differences between the study groups, for example, additional risk factors for viral detection, larger numbers are needed. This is also true for a better understanding of episodes of severe respiratory infection and the role of specific respiratory viruses and bacteria. Furthermore, sequencing and subtyping of HRV was not performed in our study, so HRV subgroups could not be analysed. In addition, the number of low-quality swabs was higher in infants with CF, which could bias the results of viral frequency in CF. To account for the differences in swab quality, we performed several sensitivity analyses. Results did not change in the different approaches, assuring the robustness of results. We suspect that the sampling quality of the swabs of infants with CF could have been lower due to a more cautious approach of the parents, or increased viscous mucus in the infants. This could be an important consideration for future study, given its relevance for the clinical setting; consideration of which is beyond the scope of the current study. The overall frequency of viral detection, however, was similar to healthy infants and concordant with what is represented in the literature. Furthermore, documentation of symptoms relied on parental reporting only, possibly resulting in an observer bias. Differences between the $\mathrm{CF}$ and healthy groups existed mainly in the reporting of nasal symptoms. It could be that parents of otherwise healthy infants are likely to report more minor symptoms, whereas parents of infants with $\mathrm{CF}$ are more accustomed to minor respiratory symptoms. However, a standardised evaluated symptom score was used in the telephone interview, which makes a systematic bias between groups unlikely.

We conclude that in the first year of life prevalence of viral detection is not more frequent in infants with CF compared with healthy controls. Infants with CF presented less often with respiratory symptoms if a virus was present. Whether this is due to local epithelial properties or immunological mechanisms is unclear. Further studies investigating the interaction of viruses, bacteria, immune responses and genetics are thus needed to better understand respiratory health in infants with CF, optimise early treatment of the disease and improve outcomes in later life.

Acknowledgements We appreciate the contribution of S Lüscher, S Schmid, G Wirz, M Graf and L Beul-Beguin (Division of Respiratory Medicine, Department of Pediatrics, Inselspital and University of Bern, Bern, Switzerland) for data collection. We thank K Landgren Hugentobler for her critical reading of the manuscript and B Spycher for biostatistical support. We thank L Müller for her consultation in virological analyses.

Collaborators Swiss Cystic Fibrosis Infant Lung Development (SCILD) cohort, current study group: Jürg Barben, MD, St. Gallen; Gaudenz Hafen, MD, Lausanne; Insa Korten, MD, Bern; Alexander Moeller, MD, Zürich; Anne Mornand, MD, Geneva; Dominik Müller-Suter, MD, Aarau; Isabelle Rochat MD, Lausanne; Florian Singer, MD, PhD, Zürich; Daniel Trachsel, MD, Basel; Sophie Yammine, MD, PhD, Bern; Maura Zanolari, MD, Bellinzona, Basel Bern Infant Lung Development (BILD) cohort, current study group: Pinelopi Anagnostopoulou, MD, Bern; Oliver Fuchs, MD, PhD, Bern; Olga Gorlanova, MD, Basel; Elena Proietti, MD, PhD, Zurich; Anne Schmidt, MD, PhD, London; Jakob Usemann, MD, Basel.
Contributors Conceived and designed project: EK, UF, NR, MH, PL. Performed the experiments: SK, MTB, MG. Analysis and interpretation of the data: IK, IM, MG, UF, MH, PL. Wrote the paper: IK, MM, MH, CK, PL. Data acquisition: IK, EK, IM, NS. Patient recruitment: EK, IM, NR, UF, PL. Critical review of the paper: all authors.

Funding The study was funded by the Swiss National Science Foundation (SNF 324730_144280/1, SNF 320030_159791), the Botnar Foundation and the German, Swiss and Austrian Society of Pediatric Pulmonology. Virus analyses were supported by BioMerieux. The funders had no role in study design, data collection and analysis, decision to publish or preparation of the manuscript.

Disclaimer The funders had no role in study design, data collection and analysis, decision to publish or preparation of the manuscript.

Competing interests None declared.

Ethics approval Ethics committee Bern, Switzerland.

Provenance and peer review Not commissioned; externally peer reviewed.

(c) Article author(s) (or their employer(s) unless otherwise stated in the text of the article) 2018. All rights reserved. No commercial use is permitted unless otherwise expressly granted.

\section{REFERENCES}

1 Olesen HV, Nielsen LP, Schiotz PO. Viral and atypical bacterial infections in the outpatient pediatric cystic fibrosis clinic. Pediatr Pulmonol 2006;41:1197-204.

2 Asner S, Waters V, Solomon M, et al. Role of respiratory viruses in pulmonary exacerbations in children with cystic fibrosis. J Cyst Fibros 2012;11:433-9.

3 Burns JL, Emerson J, Kuypers J, et al. Respiratory viruses in children with cystic fibrosis: viral detection and clinical findings. Influenza Other Respir Viruses 2012;6:218-23.

4 Chin M, De Zoysa M, Slinger R, et al. Acute effects of viral respiratory tract infections on sputum bacterial density during CF pulmonary exacerbations. J Cyst Fibros 2015:14:482-9.

5 Esther CR, Lin FC, Kerr A, et al. Respiratory viruses are associated with common respiratory pathogens in cystic fibrosis. Pediatr Pulmonol 2014;49:926-31.

6 Etherington C, Naseer R, Conway SP, et al. The role of respiratory viruses in adult patients with cystic fibrosis receiving intravenous antibiotics for a pulmonary exacerbation. J Cyst Fibros 2014;13:49-55.

7 Gangell CL, Shackleton C, Poreddy S, et al. Feasibility of parental collected nasal swabs for virus detection in young children with cystic fibrosis. J Cyst Fibros 2014;13:661-6.

8 Goffard A, Lambert V, Salleron J, et al. Virus and cystic fibrosis: rhinoviruses are associated with exacerbations in adult patients. J Clin Virol 2014;60:147-53.

9 Dijkema JS, van Ewijk BE, Wilbrink B, et al. Frequency and duration of Rhinovirus Infections in Children with cystic fibrosis and healthy Controls: a Longitudinal Cohort Study. Pediatr Infect Dis J 2016:35:379-83.

10 Flight WG, Bright-Thomas RJ, Tilston P, et al. Incidence and clinical impact of respiratory viruses in adults with cystic fibrosis. Thorax 2014;69:247-53.

11 Armstrong D, Grimwood K, Carlin JB, et al. Severe viral respiratory infections in infants with cystic fibrosis. Pediatr Pulmonol 1998;26:371-9.

12 Byrnes CA, Vidmar S, Cheney JL, et al. Prospective evaluation of respiratory exacerbations in children with cystic fibrosis from newborn screening to 5 years of age. Thorax 2013:68:643-51.

13 Bharadwaj P, Zivin JG, Mullins JT, et al. Early-Life Exposure to the Great Smog of 1952 and the Development of Asthma. Am J Respir Crit Care Med 2016;194:1475-82.

14 Postma DS, Bush A, van den Berge M. Risk factors and early origins of chronic obstructive pulmonary disease. The Lancet 2015;385:899-909.

15 Ramsey KA, Ranganathan S, Park J, et al. Early respiratory infection is associated with reduced spirometry in children with cystic fibrosis. Am J Respir Crit Care Med 2014;190:1111-6.

16 Martinez FD. Early-Life Origins of chronic obstructive pulmonary disease. N Eng/ J Med 2016:375:871-8

17 Ramsey KA, Rosenow T, Turkovic L, et al. Lung Clearance Index and Structural lung disease on Computed Tomography in Early cystic fibrosis. Am J Respir Crit Care Med 2016;193:60-7.

18 Nguyen TT, Thia LP, Hoo AF, et al. Evolution of lung function during the first year of life in newborn screened cystic fibrosis infants. Thorax 2014;69:910-7.

19 Hall GL, Logie KM, Parsons F, et al. Air trapping on chest CT is associated with worse ventilation distribution in infants with cystic fibrosis diagnosed following newborn screening. PLoS One 2011;6:e23932.

20 Pillarisetti $\mathrm{N}$, Williamson $\mathrm{E}$, Linnane $\mathrm{B}$, et al. Infection, inflammation, and lung function decline in infants with cystic fibrosis. Am J Respir Crit Care Med 2011;184:75-81.

21 Dijk FN, Fitzgerald DA. The impact of newborn screening and earlier intervention on the clinical course of cystic fibrosis. Paediatr Respir Rev 2012;13:220-5.

22 Ramsey BW, Banks-Schlegel S, Accurso FJ, et al. Future directions in early cystic fibrosis lung disease research: an NHLBI workshop report. Am J Respir Crit Care Med 2012:185:887-92.

23 Barben J, Rueegg CS, Jurca M, et al. Measurement of fecal elastase improves performance of newborn screening for cystic fibrosis. J Cyst Fibros 2016;15:313-7. 
24 Mika M, Korten I, Qi W, et al.The nasal microbiota in infants with cystic fibrosis in the first year of life: a prospective cohort study. Lancet Respir Med 2016;4:627-35.

25 Fuchs $\mathrm{O}$, Latzin $\mathrm{P}$, Kuehni $\mathrm{CE}$, et al. Cohort profile: the Bern infant lung development cohort. Int J Epidemiol 2012;41:366-76.

26 Mack I, Kieninger E, Cangiano G, et al. Rhinovirus infections and associated respiratory morbidity in Infants: a prospective Cohort Study. Pediatr Infect Dis $J$ 2016;35:1069-71.

27 Latzin P, Frey U, Roiha HL, et al.Prospectively assessed incidence, severity, and determinants of respiratory symptoms in the first year of life. Pediatr Pulmonol 2007:42:41-50.

28 Hiatt PW, Grace SC, Kozinetz CA, et al. Effects of viral lower respiratory tract infection on lung function in infants with cystic fibrosis. Pediatrics 1999;103:619-26.

29 van Ewijk BE, van der Zalm MM, Wolfs TF, et al. Prevalence and impact of respiratory viral infections in young children with cystic fibrosis: prospective cohort study. Pediatrics 2008;122:1171-6.

30 de Almeida MB, Zerbinati RM, Tateno AF, et al. Rhinovirus $C$ and respiratory exacerbations in children with cystic fibrosis. Emerg Infect Dis 2010;16:996-9.

31 Wat D, Gelder C, Hibbitts S, et al. The role of respiratory viruses in cystic fibrosis. J Cyst Fibros 2008;7:320-8.

32 Collinson J, Nicholson KG, Cancio E, et al. Effects of upper respiratory tract infections in patients with cystic fibrosis. Thorax 1996;51:1115-22.
33 Smyth AR, Smyth RL, Tong CY, et al. Effect of respiratory virus infections including rhinovirus on clinical status in cystic fibrosis. Arch Dis Child 1995;73:117-20.

34 Ramirez IA, Caverly LJ, Caverly LL, et al. Differential responses to rhinovirus- and influenza-associated pulmonary exacerbations in patients with cystic fibrosis. Ann Am Thorac Soc 2014;11:554-61.

35 Kieninger E, Vareille M, Kopf BS, et al. Lack of an exaggerated inflammatory response on virus infection in cystic fibrosis. Eur Respir J 2012;39:297-304.

36 Schögler A, Stokes AB, Casaulta C, et al. Interferon response of the cystic fibrosis bronchial epithelium to major and minor group rhinovirus infection. J Cyst Fibros 2016;15:332-9.

37 Chattoraj SS, Ganesan S, Jones AM, et al. Rhinovirus infection liberates planktonic bacteria from biofilm and increases chemokine responses in cystic fibrosis airway epithelial cells. Thorax 2011;66:333-9.

38 Kieninger E, Singer F, Tapparel C, et al. High rhinovirus burden in lower airways of children with cystic fibrosis. Chest 2013;143:782-90.

39 Rosenfeld M, Gibson RL, McNamara S, et al. Early pulmonary infection, inflammation, and clinical outcomes in infants with cystic fibrosis. Pediatr Pulmonol 2001;32:356-66.

40 Wang Y, Li Y, Liu J, et al. Genetic characterization of human Bocavirus among children with severe acute respiratory infection in China. J Infect 2016;73:155-63.

41 Kailasan S, Garrison J, llyas M, et al. Mapping antigenic epitopes on the human Bocavirus capsid. J Virol 2016;90:4670-80. 